\title{
First Right Posterolateral Artery
}

National Cancer Institute

\section{Source}

National Cancer Institute. First Right Posterolateral Artery. NCI Thesaurus. Code C102300.

In an individual with a right-dominant heart, this is the first branch that arises from the right coronary artery distal to the right posterior descending artery, when counted from proximal to distal. 